\title{
Defending 'the four principles' approach to biomedical ethics
}

\author{
Raanan Gillon Imperial College of Science, Technology and Medicine, University of London
}

In this issue of the journal a Danish physician-philosopher, Dr Søren Holm, mounts a vigorous attack (1) against the Beauchamp and Childress 'four principles' approach to biomedical ethics - an approach with which, it should be said, this author is closely associated and to which he is highly sympathetic, particularly because it seems to cut across national, cultural, religious, political and philosophical divisions and to provide a common set of prima facie moral commitments, a common moral language and a common moral-analytic framework for biomedical ethics.

Not all of Dr Holm's criticisms of the four principles approach can be addressed in a short editorial. Some responses are, however, worth making, even in summary.

The first is that readers of Dr Holm's paper who have not read the original book by Beauchamp and Childress should feel prompted to read it - in its recent fourth edition (2). As Dr Holm says, it 'is a very rich book and does reward careful study'. In particular, the four principles approach presented within its pages is entirely consistent with Dr Holm's remark that 'there is more to morality than principles'. Beauchamp and Childress explicitly affirm this. With regard to the moral importance of the virtues, good character and the moral emotions, they explain that these 'all merit attention in a comprehensive theory'. They emphasise the compatibility and mutual interdependence of virtues and principles, and remind readers of Aristotle's suggestion that ethics involves judgments rather like those of medicine: 'Principles guide us to actions, but we still need to assess a situation and formulate an appropriate response, and this assessment and response flow from character and training as much as from principles' (3).

As for Dr Holm's misleading suggestion that Beauchamp and Childress are only concerned with four virtues, this is simply false, as chapters 2,8 (on virtues and ideals in professional life) and the 17 indexed references to 'virtues' make clear. They state explicitly that of 'the many other virtues that are important to the virtuous professional' they have focused on four (compassion, discernment, trustworthiness and integrity) because they believe these to be of central importance to medical and health care ethics. And they end their book by asserting 'Almost all great ethical theories converge to the conclusion that the most important ingredient in a person's moral life is a developed character that provides the inner motivation and strength to do what is right and good' (4).

But how are people to decide or be taught what constitutes virtue and what constitutes vice, what constitutes good character and what constitutes poor character, if they do not have some guiding moral principles against which to assess people's character dispositions? On what other basis can one justify, for example, calling a disposition to care and be compassionate virtuous (and how else might one justify calling excessive or inappropriate compassion vicious, when for example its exercise overrides a recipient's rights, harms by stunting his or her emotional development, fails to respect a recipient's autonomy, or results in gross injustice to others?).

A second major line of Dr Holm's attack on the Beauchamp and Childress approach is based on Dr Holm's rejection of their account of the content of the moral obligation of beneficence. It seems clear that he himself believes the obligation of beneficence should be more demanding than it is in the account offered by Beauchamp and Childress. Pace Dr Holm, his desire is entirely consistent with the four principles approach, which in no way prevents him and others from arguing for a different account of the universal obligation of beneficence from that now presented by Beauchamp and Childress. Nonetheless their attempt to capture the necessary limitations of the universal obligation of beneficence will appeal to many. They argue that we have universal moral obligations of beneficence to others - ie, obligations to all including 'moral strangers' - when (a) those others are in major need and (b) our meeting that need would not impose on us 'significant risks, costs or burdens'. This account in no way prevents societies, groups or individuals from imposing on themselves a higher standard of obligation of beneficence.

Many in the UK, Scandinavia and other parts of Europe, and indeed in many other parts of the world, feel proud that their societies do precisely this 
in establishing and maintaining social systems, including national health systems, that look after the welfare of their needy citizens, and others whom they deem entitled to such benefits. Firemen and lifeboatmen may (and indeed should) feel proud that they commit themselves to an obligation of beneficence to those in need of their services that far exceeds the ordinary level of risk to themselves that the universal obligation of beneficence proposed by Beauchamp and Childress would require. But, pace $\mathrm{Dr}$ Holm, it seems highly unlikely that common morality in Europe or elsewhere in the world, any more than in America, would accept that the provision of health and welfare services for everyone in the world, let alone the taking of risks of the level that lifeboatmen and firemen take to benefit others in need, is part of the universal obligation of beneficence, that every one of us owes every other who is in equivalent need.

Thirdly, Dr Holm also attacks as 'simply wrong' the claim by Beauchamp and Childress that it is possible to act non-maleficently toward all persons, but it would be impossible to act beneficently toward all persons'. Readers will themselves judge $\mathrm{Dr}$ Holm's supporting argument for his claim that this 'is simply wrong', but it is an important judgment to be clear about. The force of Beauchamp and Childress's argument here is that there is a difference in the scope of application of the obligations of beneficence and of non-maleficence. If, as Dr Holm implies, this claim is false and there is no difference in scope between these prima facie obligations, then important consequences follow for practical ethics.

Specifically, it would follow that we do not have an obligation not to harm those whom we have no obligation to benefit. Now Dr Holm himself states that the moral obligation of 'beneficence must be restricted both in degree and scope'. Yet he surely does not believe that he is morally entitled to harm those whom he excludes from the scope of his obligation of beneficence. Of course not, and nor are any of us entitled to harm those to whom we have no obligation of beneficence. While we are likely to argue indefinitely about the scope of our (necessarily limited) moral obligation of beneficence, common reflective morality is likely to agree that those to whom we acknowledge no obligation of beneficence are nonetheless protected by a prima facie moral obligation of non-maleficence. One of the strengths of the Beauchamp and Childress approach to ethics is that it is grounded in common (though reflective) morality. It is common sense as well as common morality that there are fewer people in the universe whom we must benefit than there are people (and other entities) whom we must not harm.

Finally, a word about Dr Holm's criticism that the four principles approach lacks 'explicit decision rules' for when the principles conflict. Here we can all agree, for the approach has never claimed to provide such a decision mechanism, and some sort of justifiable decision procedures are badly needed.
Unfortunately we do not have any universally or even very widely agreed decision procedures for situations where agreed moral principles conflict, and it is perhaps here that the greatest effort should be directed in contemporary bioethics. Despite recent attacks on the four principles approach to bioethics, very few critics argue that any one of the four principles is incompatible with his or her preferred theory or approach to bioethics. It seems highly probable that health care workers can accept these prima facie principles, and find them compatible with whatever are their underlying or overarching moral, religious, political or philosophical theories.

Would it not therefore be useful for bioethicists to cease their attacks on the four principles approach and instead try to integrate these common morality principles (plus concern for their scope of application) into their preferred theory of health care ethics? This seems likely to require culture-specific interpretation, specification and above all harmonisation when the principles conflict. Pursuit of the latter objective is likely to require an understanding of casuistry in the sense of interpreting and applying general principles in particular cases, including an understanding of the use of paradigm cases. Such integration will certainly require understanding of the importance of good character, virtues (including the traditional medico-moral virtues of caring and compassion), conscience, and ideals, and of the importance of extensive understanding of people's real life stories and predicaments (as in 'narrative ethics') for any adequate account of health care ethics.

Bioethics is surely too young - and perhaps too fragile - a discipline to waste its energies and also its credibility on unjustified internecine warfare. Of course we must argue against claims that we believe to be wrong, especially if they seem likely to lead doctors and other health care workers to make morally bad decisions. But in doing so let us not undermine the good in others' positions. As Professor Beauchamp writes elsewhere (5), at least many of the contemporary alternative approaches to bioethics are both valuable and mutually consistent, not mutually exclusive rivals; and some of them are 'much more like good friends than hostile rivals' That is surely how it should be!

\section{References}

(1) Holm S. Not just autonomy - the principles of American biomedical ethics. Fournal of medical ethics 1995; 21: 332-338.

(2) Beauchamp T, Childress J. Principles of biomedical ethics [4th ed]. New York, Oxford: Oxford University Press, 1994.

(3) See reference (2): 67 .

(4) See reference (2): 502 .

(5) Beauchamp T. Principlism and its alleged competitors. Kennedy Institute of Ethics fournal 1995; 5: 181-198. 